\title{
Preventing pediatric tuberculosis: A randomized trial of symptom- based screening of South African children exposed to tuberculosis
}

Population Council

Follow this and additional works at: https://knowledgecommons.popcouncil.org/departments_sbsr-hiv

Part of the Demography, Population, and Ecology Commons, Family, Life Course, and Society Commons, International Public Health Commons, Maternal and Child Health Commons, and the Medicine and Health Commons

How does access to this work benefit you? Let us know!

\section{Recommended Citation}

Population Council. 2017. "Preventing pediatric tuberculosis: A randomized trial of symptom-based screening of South African children exposed to tuberculosis," Activity brief. Washington, DC: Population Council. 


\section{Preventing Pediatric Tuberculosis: \\ A Randomized Trial of Symptom-based Screening of South African Children Exposed to Tuberculosis}

HIV and tuberculosis (TB) disproportionately affect women of reproductive age in sub-Saharan Africa. Young children less than five years old are at the highest risk of developing TB upon exposure to a household member with TB disease. Isoniazid preventive therapy (IPT) is highly effective at preventing TB in these children and has long been recommended by the World Health Organization (WHO). However, a range of provider and patient challenges have hampered its implementation. WHO estimates only 7 percent of child contacts of TB index cases less than five years old worldwide receive IPT. In response, WHO has recently recommended symptom-based screening to more quickly assess child TB contacts for IPT use as opposed to traditional tuberculin skin test (TST) screening.

In South Africa, a country with one of the highest levels of HIV prevalence, HIV-positive adults are the source case for a large proportion of pediatric TB cases. Unfortunately, TB index cases are not

Research Partners: Project SOAR, Johns Hopkins University, Perinatal HIV Research Unit, Matlosana sub-district health services

Location: Matlosana sub-district of North West Province, South Africa

Study Duration: 2015-2017

For more information, contact Nicole Salazar-Austin (nsalaza1@jhmi.edu)

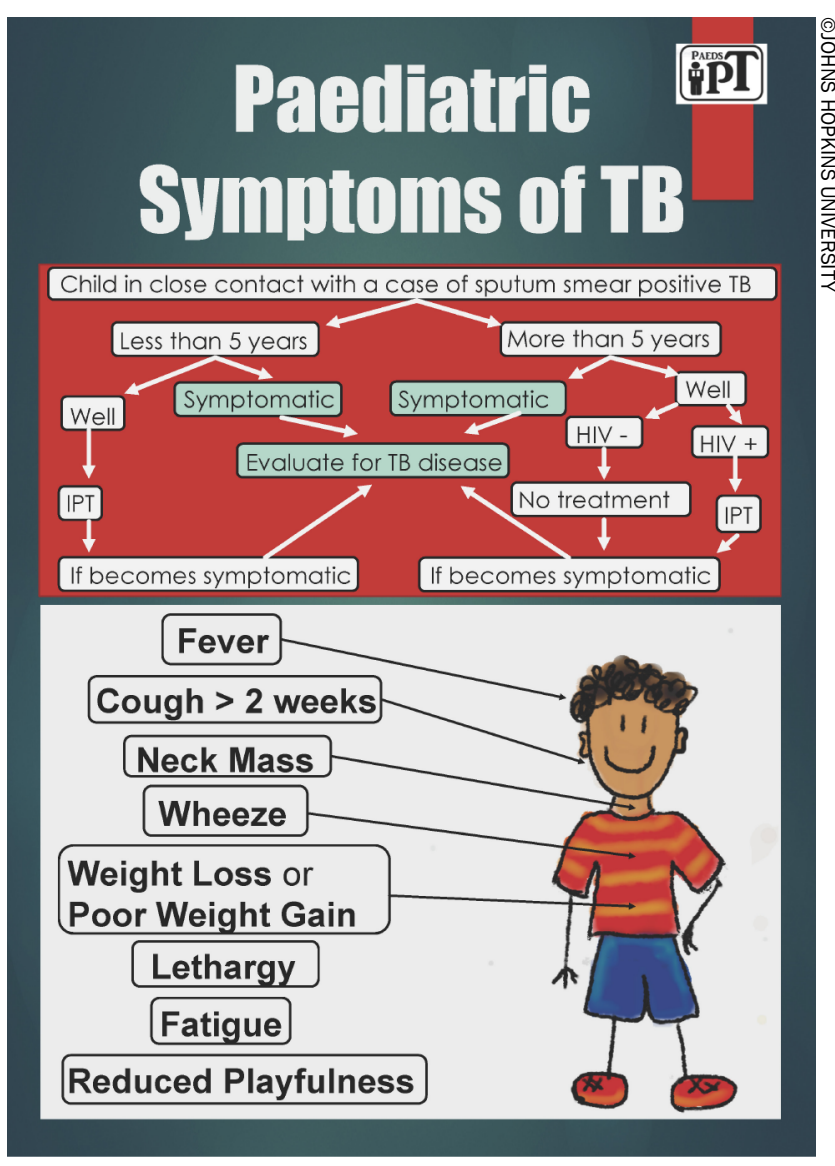

Poster outlines symptom-based screening approach TB nurses in community health clinics are following.

consistently asked about their child contacts, not all child contacts present to the clinic for TB screening, and it remains unknown what proportion of child contacts receive IPT.

Project SOAR is assessing whether a symptombased screening approach by TB nurses in community health clinics is more effective than the standard of care (TST screening) in improving the proportion of TB-exposed children initiated on IPT. 
This study will generate critical evidence to guide country and global decision-makers in strengthening health systems to more quickly identify child TB contacts and initiate life-saving IPT when warranted. This evidence is particularly important for preventing pediatric TB in South Africa and elsewhere, given the country's coepidemics of HIV and TB and low levels globally of IPT initiation.

\section{Our Research}

We are conducting a cluster-randomized trial in 16 decentralized, primary health clinics in the Matlosana sub-district of North West Province to evaluate the effect of symptom-based screening on IPT coverage among child contacts of TB index cases. We first implemented a standardized child contact patient chart and register to follow children through the contact tracing, screening, and treatment processes.

Intervention clinics: TB nurses will use symptombased screening to evaluate child contacts under five years for active TB. Symptomatic children will be referred to the district hospital for further evaluation of TB disease while asymptomatic children will be initiated on IPT by nurses at the primary health clinics.

Control clinics: TB nurses will continue to use TST to identify children at risk of TB disease. All TST-positive children and symptomatic children will require further evaluation by a pediatrician at a district hospital. TST-negative children will be initiated on IPT by nurses at the local clinic.

Children are then followed monthly for the sixmonth duration of IPT, as is the standard of care in South Africa at this time. The research team will abstract the data retrospectively from the child's chart and will provide feedback to each TB nurse every four to six weeks for the first six months of the study and then quarterly.

\section{Potential Impact}

If symptom-based screening is found to be more effective than the standard of care, it will enable TB nurses in high-burden, resource-limited, primary care settings to:

- Better identify those child contacts at higher risk of TB disease.

- Rapidly initiate IPT in healthy child contacts.

- Reduce unnecessary referrals to pediatric sub-specialists.

- Improve IPT coverage and optimize health care utilization.

\section{Research Utilization}

The research team is engaging key stakeholders in a variety of ways:

- Conducting an informal needs assessment with district health officials, hospital pediatric staff, and local nurses to ensure the study is responsive to their needs.

- Sharing clinic-specific data on the contact evaluation process with the clinic TB nurses and Nurse Manager on a quarterly basis to encourage nurse participants to improve contact tracing and IPT-related outcomes and reduce barriers to care.

- Discussing aggregate results every six months with district health officials.

- Disseminating key findings nationally and internationally through meetings, conferences, and journal manuscripts.
Project SOAR/Population Council

4301 Connecticut Avenue, NW, Suite 280

Washington, DC 20008

Tel: +1202 2379400

e-mail: ProjectSOAR@popcouncil.org

popcouncil.org/ProjectSOAR

@Population Council, February 2017 